\title{
The Distress Management System for Stroke (DMSS): An approach for screening and initial intervention for post-stroke psychological distress
}

\author{
David C. Gillespie, Amy P. Cadden \\ Astley Ainslie Hospital, NHS Lothian, Edinburgh, UK \\ Correspondence: DC Gillespie, PhD. Address: Department of Clinical Psychology, Astley Ainslie Hospital, Edinburgh, EH9 \\ 2HL, UK. Telephone: 044-0131-537-9140. Email: david.gillespie@nhslothian.scot.nhs.uk. \\ Received: March 31, 2013 \\ DOI : 10.5430/jnep.v3n10p150 \\ Online Published: July 14, 2013 \\ Accepted: May 14, $2013 \quad$ Online Publish
URL: http://dx.doi.org/10.5430/jnep.v3n10p150
}

\section{Abstract}

Aim: To develop a practical system to enable nurses to screen for psychological distress following stroke.

Background: Mood disorders and psychological distress are prevalent following stroke, but often go undetected and therefore untreated. National guidelines recommend screening for distress, but the evidence suggests that there are significant barriers to the implementation of post-stroke mood and psychological distress screening programmes. One barrier relates to limitations of questionnaire methods for identifying distress. Specifically, existing mood questionnaires are often too lengthy; miss important emotional changes that result from stroke; and do not necessarily point nurses towards the most helpful intervention approaches.

Methods: We sought to develop a brief, clinically valid screening system that could be used by nurses to identify the levels of psychological distress experienced by stroke survivors. As well as determining levels of distress, the system was intended to aid the identification of first-line interventions that nurses could offer to alleviate distress.

Results: A screening system was identified from the oncology literature (the Distress Management System [DMS]) that appeared to meet the broad requirements for screening for stroke-related distress. To tailor the DMS for stroke settings, we obtained feedback on the components of the DMS from stroke survivors and stroke nurses, and also consulted the research literature. This led us to: (1) retain the distress screening component of the DMS, the 'Distress Thermometer'; (2) modify the DMS's 'Concerns Checklist' to reflect the main problems encountered after stroke; and (3) add a 'Resource Pack' to the screening system to enable nurses to offer first-line interventions targeted at individuals' distress. The result, the Distress Management System for Stroke (DMSS), is presented in full in this paper.

Conclusion: The DMSS is a potentially useful tool for nurses working in stroke settings. It is brief, straightforward to administer, captures the main emotional concerns of stroke survivors, and the findings from the DMSS can be used to structure interventions for psychological distress. Future work is required, however, to establish the DMSS's reliability, validity and clinical effectiveness.

\section{Key words}

Psychological distress, Stroke rehabilitation, Screening, Interventions 


\section{I ntroduction}

Changes to mood and emotional well-being are common following stroke. Recent systematic review evidence indicates that approximately a third of stroke survivors suffer clinical depression ${ }^{[1]}$, and about one in four individuals experience clinically significant anxiety (e.g. generalised anxiety disorder [GAD]; panic disorder) following stroke ${ }^{[2]}$. In addition to psychiatric/psychological disorders such as these, large numbers of stroke survivors experience emotional changes that are not necessarily captured by diagnostic classifications. Therefore, the term 'psychological distress' has been proposed as a useful way to describe the wide range of emotional consequences that follow stroke. Psychological distress:

"encompasses sadness, frustration, anxiety, and a number of negative mood states. It includes both mild and severe forms of these mood states, as well as both transient and persistent ones. It also refers both to symptoms of psychiatric disorders and to normal emotional responses to adversity” $(p .5)^{[3]}$.

At the level of psychological experience, individuals describe a range of feelings such as frustration, low mood, fear of recurrent stroke, helplessness, apprehension, etc. ${ }^{[4-6]}$, and so the term captures well the spectrum of emotional changes experienced following stroke.

Besides the obvious human suffering involved, psychological distress has been shown to have a negative impact on stroke rehabilitation outcome ${ }^{[7-9]}$, and on quality of life ${ }^{[10]}$. The importance of identifying distress when it is present is underscored by evidence that distress in stroke survivors is eminently treatable, by both pharmacological ${ }^{[11]}$ and psychological treatments ${ }^{[12,13]}$. It has therefore been recommended that survivors of stroke be screened for the presence of psychological distress, in order that those who experience it might be offered appropriate interventions and care. For example, the Scottish Intercollegiate Guidelines Network recommends, "all stroke patients should be screened for mood disturbance (including those in primary care) [...] as early as appropriate and definitely before discharge, and at regular intervals thereafter" (p. 44) ${ }^{[14]}$. Similarly, the Canadian Best Practice Stroke Guidelines advise that, "all patients should be screened for depression using a validated tool", and also that healthcare professionals should be "watchful and recognize depression before it interferes significantly with therapy and the patient's well being” (p. 161) ${ }^{[15]}$.

All the available evidence, however, points to low levels of screening for post-stroke psychological distress in clinical practice. Poor compliance with mood and psychological distress screening has been reported in UK ${ }^{[16-18]}$, Australian ${ }^{[19]}$ and Canadian ${ }^{[20]}$ stroke settings. The reasons for poor compliance with psychological distress screening in stroke settings have been explored. Hart and Morris ${ }^{[17]}$ used the Theory of Planned Behaviour ${ }^{[21]}$ to investigate the barriers to screening experienced by UK stroke professionals, the largest group of whom were nurses. The major trigger for screening was found to be the presence of observable depressive symptoms, whilst the main barrier to screening was insufficient staff time. The study also discovered that negative influences on screening included feeling uncomfortable using standardised multi-item questionnaires, and perceiving that screening was not a useful clinical activity because it failed to provide information that helped with the selection of treatments. These findings have been echoed in other studies looking at the implementation of stroke rehabilitation evidence into guidelines ${ }^{[22,23]}$, and prompted the authors of the current paper to investigate alternatives to questionnaire methods of screening for post-stroke psychological distress. We specifically sought an alternative that was brief, low-cost, tailored - or able to be tailored - to individuals with stroke, and that would allow the results of screening to be linked to treatment options in a more obvious way. Fortunately, such an alternative has been described in the oncology literature, and is already an established component of many clinical oncology services: the Distress Management System ${ }^{[24]}$.

\section{The Distress Management System}

The Distress Management System (DMS) was designed to assess psychological distress in individuals with cancer, a condition that is often associated, like stroke, with high levels of emotional disturbance ${ }^{[25]}$. The DMS was devised to 
reduce the discomfort that individuals with cancer may have in acknowledging emotional difficulties on formal questionaires. The term 'distress' was chosen as a potentially less stigmatising alternative to 'anxiety' or 'depression', because it is a term that is less likely to pathologise the wide range of normal experiences associated with being diagnosed with cancer ${ }^{[25]}$. The DMS comprises two components, namely: (a) a 'Distress Thermometer'; and (b) a 'Concerns Checklist', which are now described in turn.

Roth and colleagues introduced the first component of the DMS, the Distress Thermometer, as a quick screening tool to measure psychological distress in busy cancer care settings ${ }^{[26]}$. The concept is straightforward. The Distress Thermometer comprises a visual analogue scale resembling a mercury thermometer, with 11 increments that range from 0 ('no distress') to 10 ('extreme distress'). Individuals are invited to "circle the number (0-10) that best describes how much distress you have been experiencing in the past week, including today" ${ }^{[24]}$. After an individual's level of distress has been determined, he or she is presented with a Concerns Checklist, which is the second component of the DMS.

The Concerns Checklist is a catalogue of problems (34 in the original version of the instrument ${ }^{[24]}$ grouped into five categories: Practical problems (e.g. childcare, transport); Family problems (e.g. dealing with children); Emotional problems (e.g. fears, sadness); Spiritual/religious concerns (e.g. loss of faith, loss of meaning or purpose in life); and Physical problems (e.g. nausea, breathing, pain). The individual is asked to indicate whether any of the problems on the checklist have been a concern to them in the past week. The nurse therefore obtains an overall measure of distress, as well as an idea of the current issues that are impacting on a person's distress. Knowing an individual's most pressing concerns (e.g. transport; worry; discomfort, etc.) provides nurses with clues as to potentially helpful interventions (e.g. assistance with transport problems; information about relaxation techniques; medication review for nausea or pain, etc.).

The National Comprehensive Cancer Network (NCCN) guidelines ${ }^{[24]}$ recommend that each new cancer patient is rapidly assessed for evidence of distress using the DMS. Of relevance to busy clinical settings is the finding that the median time to complete the DMS is 5 minutes (with $75 \%$ of people taking no more than 10 minutes) ${ }^{[27]}$. Scores on the Distress Thermometer component have been validated against standardised instruments such as the Hospital Anxiety and Depression Scale (HADS) ${ }^{[27,28]}$ and the General Health Questionnaire (GHQ) ${ }^{[27]}$. However, it is important to note that the Distress Thermometer was not designed as a diagnostic tool, and so perfect correspondence between Distress Thermometer ratings and scores on standardised measures of mood are not necessarily expected, and hard-and-fast cutoffs to distinguish normal from abnormal scores may be difficult to determine ${ }^{[29]}$. Rather, the strength of the DMS is that it offers a method by which nurses can open up communication with individuals about distress, and also ways to identify the key source(s) of distress.

\section{The Distress Management System for Stroke (DMSS)}

Although the DMS has been shown to be valid and practicable in cancer settings ${ }^{[25-28]}$, and has been identified as potentially useful for the stroke population ${ }^{[30]}$, there do not appear to be any published accounts that detail the adaptation of the system from cancer to stroke settings. Differences exist between cancer and stroke populations, and so it does not automatically follow that the same distress management approach, without modification, would be equally valid for both conditions. To take an example, cognitive and communication problems, which might impact on individuals' ability to undertake the DMS, are more common following stroke than cancer. Also, the types of problems and main sources of distress appear to differ between the two illnesses ${ }^{[31]}$. In the following sections we set out the steps we took to adapt the DMS for use in stroke settings.

\subsection{Modifying the DMS for stroke}

The first step was to modify the DMS in order to reflect the concerns of most importance to individuals with stroke. These modifications were informed by a review of relevant stroke guidelines ${ }^{[14,15]}$, and by seeking the opinions of stroke survivors and stroke nurses, specifically their feedback on the two main components of the DMS. Eight post-acute 
inpatient stroke rehabilitation nurses and seven stroke patients (four women, three men) in Edinburgh, UK were interviewed. All patients were within the first six months of stroke onset. Interviewees were asked three questions about the DMS to determine the perceived suitability of the screening approach for individuals with stroke (see Table 1).

Table 1. Interview questions and sample responses

\begin{tabular}{|c|c|c|}
\hline \multirow{2}{*}{ Question } & \multicolumn{2}{|c|}{ Response } \\
\hline & Patient & Staff \\
\hline $\begin{array}{l}\text { In this questionnaire we used } \\
\text { the word "distress"; do you } \\
\text { feel this is the right word to } \\
\text { use? }\end{array}$ & $\begin{array}{l}\text { “The word 'distress' is OK but other words } \\
\text { such as 'annoyance' or 'frustration' may } \\
\text { also be helpful”. }\end{array}$ & $\begin{array}{l}\text { "It is OK. It may not be suitable for everyone } \\
\text { therefore an explanation of what was meant by } \\
\text { 'distress' would be useful”. }\end{array}$ \\
\hline $\begin{array}{l}\text { Do you feel the categories } \\
\text { included in this questionnaire } \\
\text { are suitable and make sense? } \\
\text { If not how do you feel they } \\
\text { could be improved? }\end{array}$ & $\begin{array}{l}\text { "I feel it is well laid out and makes sense". } \\
\text { "For me physical concerns are very } \\
\text { important and I feel that all aspects are } \\
\text { covered". } \\
\text { "I feel that everything belongs there". }\end{array}$ & $\begin{array}{l}\text { "I feel it was very good to start with physical } \\
\text { concerns as fears over walking, eating and drinking } \\
\text { are often the most important initial concerns". } \\
\text { "Communication, especially expressive, is a very } \\
\text { big issue". } \\
\text { "I feel all of the key areas are covered”. }\end{array}$ \\
\hline $\begin{array}{l}\text { Do you think any additional } \\
\text { categories should be added? } \\
\text { If so what would they be? }\end{array}$ & $\begin{array}{l}\text { "I can't think of anything, I feel all the } \\
\text { categories make sense". }\end{array}$ & $\begin{array}{l}\text { "Fear over going home is a common source of } \\
\text { anxiety so I think it would be useful to have } \\
\text { information available in the community to aid in } \\
\text { transition and adjustment”. }\end{array}$ \\
\hline $\begin{array}{l}\text { Do you think the } \\
\text { questionnaire is user } \\
\text { friendly? In other words, if } \\
\text { someone was to measure how } \\
\text { you felt over the past week, } \\
\text { do you feel this is a good way } \\
\text { to tell how you are doing? }\end{array}$ & $\begin{array}{l}\text { "Yes, it was quite straightforward and would } \\
\text { be easy to fill out. It is well laid out and easy } \\
\text { to use". }\end{array}$ & $\begin{array}{l}\text { "Yes, I feel it is user friendly from a staff point of } \\
\text { view”. }\end{array}$ \\
\hline
\end{tabular}

\subsection{The Distress Management System for Stroke (DMSS)}

The first question asked about the use of the term 'distress'. Staff highlighted the need to provide stroke survivors with a short explanation about what was meant by the term, and suggested the addition of the words "if any" to prevent the distress screening question from being too leading. In the DMSS the screening question therefore reads "Please circle the number below (0-10) that describes how much distress, if any, you have felt over the past week". This is a simple, but important alteration, because it recognises that a proportion of stroke survivors experience emotional blunting, in which their subjective experience is a complete or near-complete absence of distress or concern ${ }^{[32]}$.

Modifications were also made in response to the question we posed about the Concerns Checklist. The number of concerns was reduced from the 34 in the DMS to 23 in the DMSS, which we organised into seven categories (see Figure 1). By reducing the overall number of concerns, the stroke Concerns Checklist was simplified for individuals with cognitive impairment. The decision was also taken to ask individuals to identify their "Top Priority" if more than one concern was chosen from the checklist; this addition was made to help people think about the issues that might need to be tackled first, and to encourage the person with stroke to set the agenda. This makes a natural fit with goal setting approaches in stroke rehabilitation ${ }^{[14]}$.

The DMSS categories included the five originally outlined in the cancer version with some minor adjustments to wording (e.g. 'Family Problems' was replaced by 'Relationships' to help individuals to discriminate family from non-family relational distress) and the addition of two new categories, 'Mental Abilities' and 'Communication'. The latter categories were chosen because changes to cognition, and to receptive and expressive communication are prevalent after stroke, and 


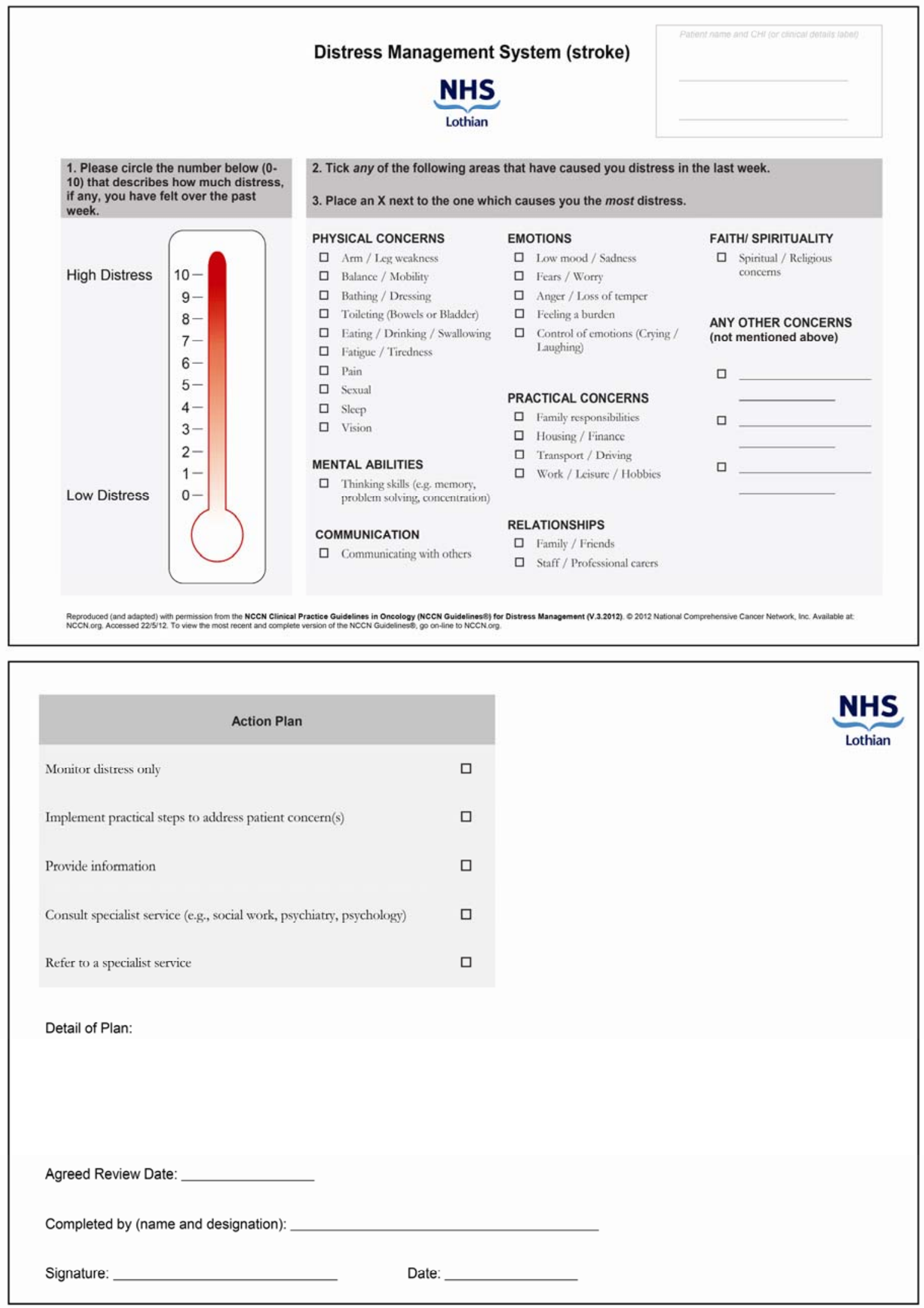

Figure 1. Distress management system 
have been shown to be among the most difficult to manage consequences of stroke illness ${ }^{[6,14]}$. Some cancer physical concerns were excluded from the DMSS (e.g. 'feeling swollen'; 'nausea and vomiting'; 'skin itchy or dry'; 'breathing') as these problem areas were not specifically mentioned in the stroke rehabilitation guidelines we consulted ${ }^{[14,15]}$, and nor were they identified in a comprehensive study of the main subjective problems experienced after stroke ${ }^{[33]}$.

Finally, we added a component to the DMSS to extend the clinical usefulness of the distress management system as outlined in the published NCCN cancer guidelines ${ }^{[24]}$. The additional component is a 'Resource Pack'. The Resource Pack is a box file containing separate sections for all 23 issues in the stroke Concerns Checklist. Each section of the box file contains between two and four written pieces of information per concern; some for stroke survivors (e.g. leaflets; 'tips' for coping with a difficulty), and some for the nurse administering the DMSS (e.g. referral pathways; ideas for symptom management for specific stroke-related conditions). Importantly, we included a rating scale for depression, the PHQ-9 ${ }^{[34]}$, which is administered if an individual identifies 'Low mood/Sadness' on the Concerns Checklist, or if the person administering the DMSS is concerned that a stroke survivor may be depressed. A number of the written materials, compiled in consultation with stroke professionals and following a review of online resources from the UK stroke charities Chest Heart and Stroke Scotland (CHSS) and the Stroke Association, were purposely shortened for people with cognitive problems, and some were constructed using pictorial materials for people with communication problems.

Research has found that information is considered by stroke survivors to be a vitally important component of care ${ }^{[35]}$, but in most cases individuals perceive gaps in the information they have received ${ }^{[36]}$. In other words, the DMSS Resource Pack meets a documented clinical need, and complements the distress screening aspect of the DMSS by helping nurses to decide on first-line interventions for distressed stroke survivors.

\section{Conclusion}

Screening for psychological distress after stroke - i.e., asking all stroke survivors how they feel, not just those displaying the obvious outward signs of distress - is important. This is because individuals may choose to minimize or hide their underlying feelings, perhaps for reasons of shame or embarrassment ${ }^{[37]}$, and only specific - and sensitive - enquiry will allow their actual level of distress to be determined. The main uncertainty for healthcare professionals, as already indicated, relates to the most appropriate tool with which to screen for psychological distress, for existing methods (e.g. mood questionnaires) have been shown to have considerable limitations.

The Distress Management System for Stroke (DMSS), as described in this paper, is a potentially useful addition to the stroke nurse's assessment toolkit. The DMSS is brief, covers the main distress-related concerns for people with different types of stroke (mild through to severe stroke, and also ischaemic as well as haemorrhagic stroke), is straightforward to complete for individuals with cognitive or communication problems, and has the advantage of being free to use - an important consideration in the current financial climate for healthcare services. What is more, the DMSS can be used at different time points following stroke (i.e. from days to years after the event) given that distress can occur any time after stroke onset ${ }^{[1,2,6]}$, and in view of the fact that the problems covered by the Concerns Checklist are relevant to new-onset as well as long-standing strokes ${ }^{[14,15,33]}$.

We also believe that the DMSS offers a potentially less stigmatising method than traditional mood questionnaires to enquire about the wide range of emotional disturbances that follow stroke. The stroke survivors we interviewed were comfortable with the term 'distress', and all felt that they could engage in conversations with nurses about the issues that related most closely to their underlying feelings. This is consistent with research showing that the cancer care DMS, on which the DMSS was based, is highly acceptable to patients. In one study, very few patients (only 6.6\%) refused to complete the DMS ${ }^{[26]}$, and when individuals in another study were asked "Did filling it in upset you in any way?" 95\% of respondents answered "no" ${ }^{[27]}$. The latter finding is especially noteworthy, for a recent stroke study found that staff 
avoided screening for psychological distress in the apparently mistaken belief that individuals would be upset by being asked about their feelings, or that screening might actually trigger depression ${ }^{[17]}$.

Over and above this, the DMSS as a method of screening is compatible with stepped care approaches to meeting the psychological needs of stroke survivors. In the UK, the Royal College of Physicians ${ }^{[38]}$, the National Institute for Health and Clinical Excellence (NICE) ${ }^{[39]}$, and the NHS Stroke Improvement Programme ${ }^{[40]}$ all recommended psychological stepped care for stroke services. Put simply, the aim of stepped care is to offer psychological support in a hierarchical way, with simple interventions first (Level 1), and more complex interventions (Levels 2 and 3) if individuals require them. Level 1 support for mild distress might include simple education and advice; Level 2 support for moderate distress might involve structured support by professionals with appropriate training and supervision; Level 3 support for the highest levels of distress would be provided by mental health specialists. Because the majority of stroke services have relatively limited access to Level 3 support ${ }^{[16]}$, nurses have a vitally important role in the recognition and initial management of stroke survivor distress ${ }^{[41]}$, and can employ the DMSS to structure their work at the first levels of a stepped care model.

Specifically, the assessment of psychological distress using the Distress Thermometer would constitute a stepped care Level 1 activity. The ability to work with distressed individuals using, for example, reflective listening skills is a competence addressed by most professional nursing programmes ${ }^{[42]}$. Level 2 activities (e.g. relaxation training, goal setting, psycho-education) could be undertaken by nurses using the DMSS Resource Pack materials, perhaps with supervision or support from a psychologist or professional with psychological expertise. The benefits of first-line interventions for mild to moderate problems are clear: Problems could be 'nipped in the bud' if addressed early enough, so that distress would not escalate to the point that an individual required specialist psychological referral. Indeed, evidence has emerged that it is possible to prevent post-stroke depression by providing low-intensity approaches to individuals whose current levels of psychological distress are below the threshold for psychological or psychiatric diagnosis ${ }^{[43]}$.

In this paper we have outlined an approach to the screening and initial intervention for psychological distress that, to our knowledge, has not been described in the stroke literature before. As with any new approach, work must be carried out to determine the reliability and validity of the DMSS, in a range of stroke healthcare settings (e.g. hospital and community), with individuals who have different stroke deficits (e.g. communication problems; poor insight). The manner in which the DMSS is delivered is, of course, likely to influence its effectiveness. For instance, research has demonstrated the importance of using health behaviour change principles (e.g. building self-efficacy; working with ambivalence) when discussing the distress-related concerns of people who have long-term conditions ${ }^{[44]}$. The DMSS allows nurses to structure their discussions with stroke survivors along these lines, and therefore to positively influence patient outcomes.

\section{Acknowledgements}

The authors wish to acknowledge the contribution of Dr Marion Murray to discussions about psychological distress screening after stroke, and also to acknowledge the patients and nurses on the Stroke Unit, Astley Ainslie Hospital who took the time to provide feedback on the DMSS. Funding for this work was provided by Chest Heart and Stroke Scotland (CHSS).

\section{Competing interests}

The authors declare that they have no competing interests.

\section{References}

[1] Hackett ML, Yapa C, Parag V, Anderson CS. Frequency of depression after stroke: A systematic review of observational studies. Stroke. 2005; 36: 1130-1340. http://stroke.ahajournals.org/content/36/6/1330.full.pdf+html.

http:dx.doi.org/10.1161/01.STR.0000165928.19135.35 
[2] Campbell Burton CA, Murray J, Holmes J, Astin F, Greenwood D, Knapp P. Frequency of anxiety after stroke: A systematic review and meta-analysis of observational studies. Int J Stroke, in press. PMid:23013268

[3] Carney RM, Freedland KE. Psychological distress as a risk factor for stroke-related mortality. Stroke. 2002; 33: 5-6. http://stroke.ahajournals.org/content/33/1/5.full.pdf+html. PMid:11779880

[4] Smith LN, Lawrence M, Kerr SM, Langhorne P, Lees, KR. Informal carers’ experience of caring for stroke survivors. JAN. 2004; 46: 235-244. http://dx.doi.org/10.1111/j.1365-2648.2004.02983.x

[5] Gillespie DC, Joice S, Lawrence M, Whittick J. Interventions for post-stroke disturbances of mood and emotional behaviour: A review of SIGN 118 stroke rehabilitation guideline recommendations. Int J Ther Rehabil. 2011; 18: 545-553.

[6] White JH, Magin P, Attia J, Sturm J, Carter G, Pollack M. Trajectories of psychological distress after stroke. Ann Fam Med. 2012; 10: 435-442. http://dx.doi.org/10.1370/afm.1374

[7] Herrmann N, Black SE, Lawrence J, Czekely C, Szalai JP. The Sunnybrook Stroke Study: A prospective study of depressive symptoms and functional outcomes. Stroke. 1998; 29: 618-624. http://dx.doi.org/ 10.1161/01.STR.29.3.618

[8] Pohjasvaara T, Vataja R, Leppavuori A, Kaste M, Erkinjuntti T. Depression is an independent predictor of poor long-term outcome post-stroke. Eur J Neurol. 2001; 8: 315-319. http://dx.doi.org/10.1046/j.1468-1331.2001.00182.x

[9] Schmid AA, Kroenke K, Hendrie HC, Bakas T, Sutherland JM, Williams LS. Poststroke depresson and treatment effects on functional outcomes. Neurology. 2011; 76: 1000-1005. http://www.neurology.org/content/76/11/1000.full.pdf+html. PMid:21403112 http://dx.doi.org/10.1212/WNL.0b013e318210435e

[10] Morris JH, van Wijck F, Joice S, Donaghy M. Predicting health related quality of life 6 months after stroke: The role of anxiety and upper limb dysfunction. Disabil Rehabil. 2013; 35: 291-299. PMid:22691224 http://dx.doi.org/10.3109/09638288.2012.691942

[11] Hackett ML, Anderson CS, House AO. Management of depression after stroke: A systematic review of pharmacological therapies. Stroke. 2005; 36: 1092-1097. PMid:15802637 http://dx.doi.org/10.1161/01.STR.0000162391.27991.9d

[12] Rasquin SMC, van de Sande P, Praamstra J, van Heugten CM. Cognitive-behavioural intervention for depression after stroke: Five single case studies of effects and feasibility. Neuropsychol Rehabil. 2009; 19: 208-222. http://dx.doi.org/10.1080/09602010802091159

[13] Thomas S, Walker M, MacNiven J, Haworth H, Lincoln NB. Communication and Low Mood (CALM): A randomized controlled trial of behavioural therapy for stroke patients with aphasia. Clin Rehab, in press.

[14] Scottish Intercollegiate Guidelines Network (SIGN). Management of Patients with Stroke: Rehabilitation, Prevention and Management of Complications, and Discharge Planning. 2010; SIGN Publication 118. www.sign.ac.uk/guidelines/fulltext/118/index.html

[15] Lindsay MP, Gubitz G, Bayley M, Hill MD, Davies-Schinkel C, Singh S, et al. Canadian Best Practice Recommendations for Stroke Care (Update 2010). On behalf of the Canadian Stroke Strategy Best Practices and Standards Writing Group. 2010; Ottawa, Ontario Canada: Canadian Stroke Network.

[16] Bowen A, Knapp P, Hoffman A, Lowe D. Psychological services for people with stroke: Compliance with the UK National Clinical Guidelines. Clin Rehabil. 2005; 19: 323-330. http://cre.sagepub.com/content/19/3/323.full.pdf+html?hwoaspck=true. http://dx.doi.org/10.1191/0269215505cr799oa

[17] Hart S, Morris R. Screening for depression after stroke: an exploration of professionals' compliance with guidelines. Clin Rehab. 2008; 22: 60-70. http://dx.doi.org/10.1177/0269215507079841

[18] Morris R, Jones J, Wilcox J, Cole S. Depression and anxiety screening after stroke: Adherence to guidelines and future directions. Disabil Rehabil. 2012; 34: 733-739. http://informahealthcare.com/doi/abs/10.3109/09638288.2011.619623. PMid:22004692 http://dx.doi.org/10.3109/09638288.2011.619623

[19] Luker JA, Bernhard J, Grimmer-Somers KA. Demographic and stroke-related factors as predictors of quality of acute stroke care provided by allied health professionals. J Multidiscip Healthc. 2011; 4: 247-259. http://dx.doi.org/10.2147/JMDH.S22569

[20] Salter K, McClure A, Mahon H, Foley N, Teasell R. Adherence to Canadian Best Practice recommendations for stroke care: Assessment and management of poststroke depression in an Ontario rehabilitation facility. Top Stroke Rehabil. 2012; $19: 132-140$. http://dx.doi.org/10.1310/tsr1902-132

[21] Ajzen I. From intentions to action; A theory of planned behavior. In Action Control: From Cognitions to Behaviors. J Kuhl, J Beckham, eds. Heidelberg: Springer, 1985, 11-39.

[22] Rochette A, Korner-Bitensky N, Desrosiers J. Actual vs best practice for families post-stroke according to three rehabilitation disciplines. J Rehabil Med. 2007; 39: 513-519. http://dx.doi.org/10.2340/16501977-0082

[23] Bailey MT, Hurdowar A, Richards CL, Korner-Bitensky N, Wood-Dauphinee S, Eng JJ, et al. Barriers to implementation of stroke rehabilitation evidence: Findings from a multi-site pilot project. Disabil Rehabil. 2012; 34: 1633-1638. PMid:22631218 http://dx.doi.org/10.3109/09638288.2012.656790 
[24] National Comprehensive Cancer Network (NCCN). Clinical Practice Guidelines in Oncology. 2009. www.nccn.org/professionals/physician_gls/f_guidelines.asp\#supportive (24 March 2013, date last accessed).

[25] Lynch J, Goodhart F, Saunders Y, O’Connor SJ. Screening for psychological distress in patients with lung cancer: Results of a clinical audit evaluating the use of the patient Distress Thermometer. Support Care Cancer. 2011; 19: 193-202. PMid:20069436 http://dx.doi.org/10.1007/s00520-009-0799-8

[26] Roth AJ, Kornblith AB, Batel-Copel L, Peabody E, Scher HI, Holland JC. Rapid screening for psychologic distress in men with prostate carcinoma - A pilot study. Cancer. 1998; 82: 1904-1908. http://dx.doi.org/10.1002/(SICI)10970142(19980515)82:10<1904::AID-CNCR13>3.0.CO;2-X

[27] Gessler S, Low J, Daniells E, Williams R, Brough V, Tookman A, et al. Screening for distress in cancer patients: Is the distress thermometer a valid measure in the UK and does it measure change over time? A prospective validation study. Psychooncology. 2008; 17: 538-547. http://onlinelibrary.wiley.com/doi/10.1002/pon.1273/pdf. PMid:17973237 http://dx.doi.org/10.1002/pon.1273

[28] Mitchell, AJ. Polled results from 38 analyses of the accuracy of distress thermometer and other ultra-short methods of detecting cancer-related mood disorders. J Clin Oncology. 2007; 25: 4670-4681. http://dx.doi.org/0.1200/JCO.2006.10.0438

[29] Patel D, Sharpe L, Thewes B, Bell ML, Clarke S. Using the Distress Thermometer and Hospital Anxiety and Depression Scale to screen for psychosocial morbidity in patients diagnosed with colorectal cancer. J Affect Disord. 2011; 131: 412-416. http://dx.doi.org/10.1016/j.jad.2010.11.014

[30] Williams L, Thomson A, Lowden L. MCN for stroke distress management system. Int J Stroke. 2010; 5 (suppl 3): 28.

[31] Clarke DM, Currie KC. Depression, anxiety and their relationship with chronic diseases: A review of the epidemiology, risk and treatment evidence. MJA. 2009; 190: S54-S60. PMid:19351294

[32] Paradiso S, Ostedgaard K, Vaidya J, Ponto LB, Robinson R. Emotional blunting following left basal ganglia stroke: The role of depression and fronto-limbic functional alterations. Psychiatry Res. 2013; 211: 148-159.

http://dx.doi.org/10.1016/j.pscychresns.2012.05.008

[33] deWeerdt, WJG, Harrison MA. Problem list of stroke patients as identified in the problem orientated medical record. Aust J Physiother. 1985; 31: 146-150.

[34] Kroenke K, Spitzer RL, Williams JBW. The PHQ-9: Validity of a brief depression severity measure. J Gen Intern Med. 2001; 16: 606-613. http://dx.doi.org/10.1046/j.1525-1497.2001.016009606.x

[35] Pound P, Bury M, Gompertz P, Ebrahim S. Stroke patients' views on their admission to hospital. BMJ. 1995; 311: 18-22. PMid:7613315 http://dx.doi.org/10.1136/bmj.311.6996.18

[36] Tooth L, Hoffmann T. Patient perceptions of the quality of information provided in a hospital stroke rehabilitation unit. Br J Occ Th. 2004; 67: 111-117.

[37] Carlsson GE, Moller A, Blomstrand C. A qualitative study of the consequences of 'hidden dysfunctions' one year after a mild stroke in persons < 75 years. Disabil Rehabil. 2004; 26: 1373-1380. http://dx.doi.org/10.1080/09638280400000211

[38] Intercollegiate Working Party for Stroke. National Clinical Guidelines for Stroke (Fourth Edition). 2012; London: Royal College of Physicians.

[39] National Institute for Health and Clinical Excellence. Depression: The Treatment and Management of Depression in Adults (update). NICE. 2010: www.nice.org.uk/nicemedia/pdf/Depression_Update_FULL_GUIDELINE.pdf

[40] Gillham S, Clark L. Psychological Care After Stroke: Improving Stroke Services for People with Cognitive and Mood Disorders. 2011; Leicester, UK: NHS Improvement. www.improvement.nhs.uk/stroke/

[41] Lightbody CE, Baldwin R, Connolly M, Gibbon B, Jawaid N, Leathey M, et al. Can nurses help identify patients with depression following stroke? A pilot study using two methods of detection. J Adv Nursing. 2007; 57: 505-512.

http://onlinelibrary.wiley.com/doi/10.1111/j.1365-2648.2006.04135.x/pdf. PMid:17284278

http://dx.doi.org/10.1111/j.1365-2648.2006.04135.x

[42] Mitchell ML, Henderson A, Groves M, Dalton M, Nulty D. The Objective Structured Clinical Examination (OSCE): Optimising its value in the undergraduate nursing curriculum. Nurse Educ Today. 2009; 29: 398-404. http://dx.doi.org/10.1016/j.nedt.2008.10.007

[43] Hackett ML, Anderson CS, House A, Halteh C. Interventions for preventing depression after stroke. Cochrane Database Syst Rev. 2008: CD003689. http://dx.doi.org/10.1002/14651858.CD003689.pub3

[44] Nicklas, L, O’Brien G, Torrens L, Wallace L. AsSET: A psychological training package for the 'real world'. Primary Health Care. 2012; 22: 26-31. 